\title{
VI. An attempt to arrange the crystals of oxidated tin ore, according to their supposed structure
}

\author{
Mr. William Day
}

To cite this article: Mr. William Day (1799) VI. An attempt to arrange the crystals of oxidated tin ore, according to their supposed structure, Philosophical Magazine Series 1, 4:14, 152-160, DOI: $10.1080 / 14786449908677047$

To link to this article: http://dx.doi.org/10.1080/14786449908677047

曲 Published online: 18 May 2009.

Submit your article to this journal $\lceil\pi$

Џ Article views: 4

Q View related articles $\square$ 
times eggs, potatoes, \&c. We had an uncommonly pleafant voyage home, and confant fine weather, accompanied with northerly breezes.

We arrived about the latter end of Auguft fafe in Greenland Dock, after having been out five months.

Captain Souter kept an excellent table in the cabin, and a conftant fire in the ftove: his ftudy was to make every perfon on board comfortable. In the fifteen voyages I have been to fea, I have only twice had the good fortune to fail with men of equal worth; Mr. Charles Patterfon of the Sea Horfe, and Mr. William Alder, now a Lieutenant in the Britifh Navy.

VI. An Attempt to arrange the Cryftals of Oxidated Tin Ore, according to tbeir fupposed Strueture. By Mr. WitI I M DAY, Leicefter Place. Communicated by the Autbor.

THE cryftallifations of oxidated tin ore are defcribed by Romé de l'Ine, in his Criftallography, to be of the octaedral form and its modifications; the octaedra having ifofceles triangular faces, inclined at an angle of $45^{\circ}$ to the bafe of each pyramid; fo that the junction of their bafes and apices are right angles. In the following arrangement the octaedron is confidered as the primitive form, and the modifications as being produced by an accumulation, on its faces, of laminæ compofed of fimilar minute moleculæ, experiencing different laws of decrement on their fides ar angles, or on both, Thefe laws of decrement are marked with the figns invented by Hauy, of which an account has been given in the Phil. Mag. Vol. II. p. 398. The greater part of thefe forms having been very accurately defcribed by De l'Ine, all that is now attempted is an application of Hauy's fyftem to the arrangement of this part of a private cabinet of Englifh minerals; nor would it have been made public but for the repeated folicitations of feveral friends. 
In the annexcd drawing (fee plate III.) all the plans, and alfo the figures marked $\mathrm{I} a, \mathrm{I} b$, and $\mathrm{I} c$, are geometrical: the others are drawings from models, and in perfpective as they appear to the eye; but all of them placed in the fame relative fituation to the nucleus, fig. $x$., on which they are fuppofed to be formed. Mathematical correctnefs is not attempted, nor is it neceflary. The prifms are fhewn with the pyramid on one end only; not on both, as in Del'Ine's plates.

Fig. I, a perfpeetive view of the primitive oetaedron of oxidated tin ore. I $a$, a front geometrical elevation, with the quantity of the angles marked upon them. I $b$, an angular gcometrical elevation, allo with the quantity of the angles marked upon them. I $c$, one of the faces of the octacdron, fubdivided to thew the fuppofed arrangement of the primitive molecule that form one lamina. The dark triangles reprefent the fpaces they occupy refpectively, and the difference of fhading, the progrefs of diminution by a fubtraction of one range of molecula on the edges of the faces, according to the third law of decrement. The fuperior angle A of this face is $70^{\circ}$, the two inferior angtes $\mathrm{E}, \mathrm{E}, 55^{\circ}$ each. The letters on the three geometrical figures mark the fame fituations on all of them, and are thole employed by Flauy to indicate the laws of decrement.

As Hauy's fy/lim has been given in the Firft Volume of the Philofoptrical Magazine, and his figits in the Second, little more is requircd here but to give the fign to which the figures belong.

$$
\text { Firfl Law of Decrement } \stackrel{\mathrm{D}}{\mathbf{1}} \text {. }
$$

To this law belong fig. 2, 3, and 4. Fig. $2 a$, without the dotted lines, would reprefént a plan of fig. 2. That portion of fig. $2 a$, included beiween the dotted lines $b b, b b$, reprefents a plan of fig. 3. The plan of fig. 4 is evident from the figure.

Second Law of Decrement iE.

Fig. 5 belongs to this law: fig. $2 a$, the angles being taken off at the dotted lines, reprefents a plan of it. Fig. 6 is a 

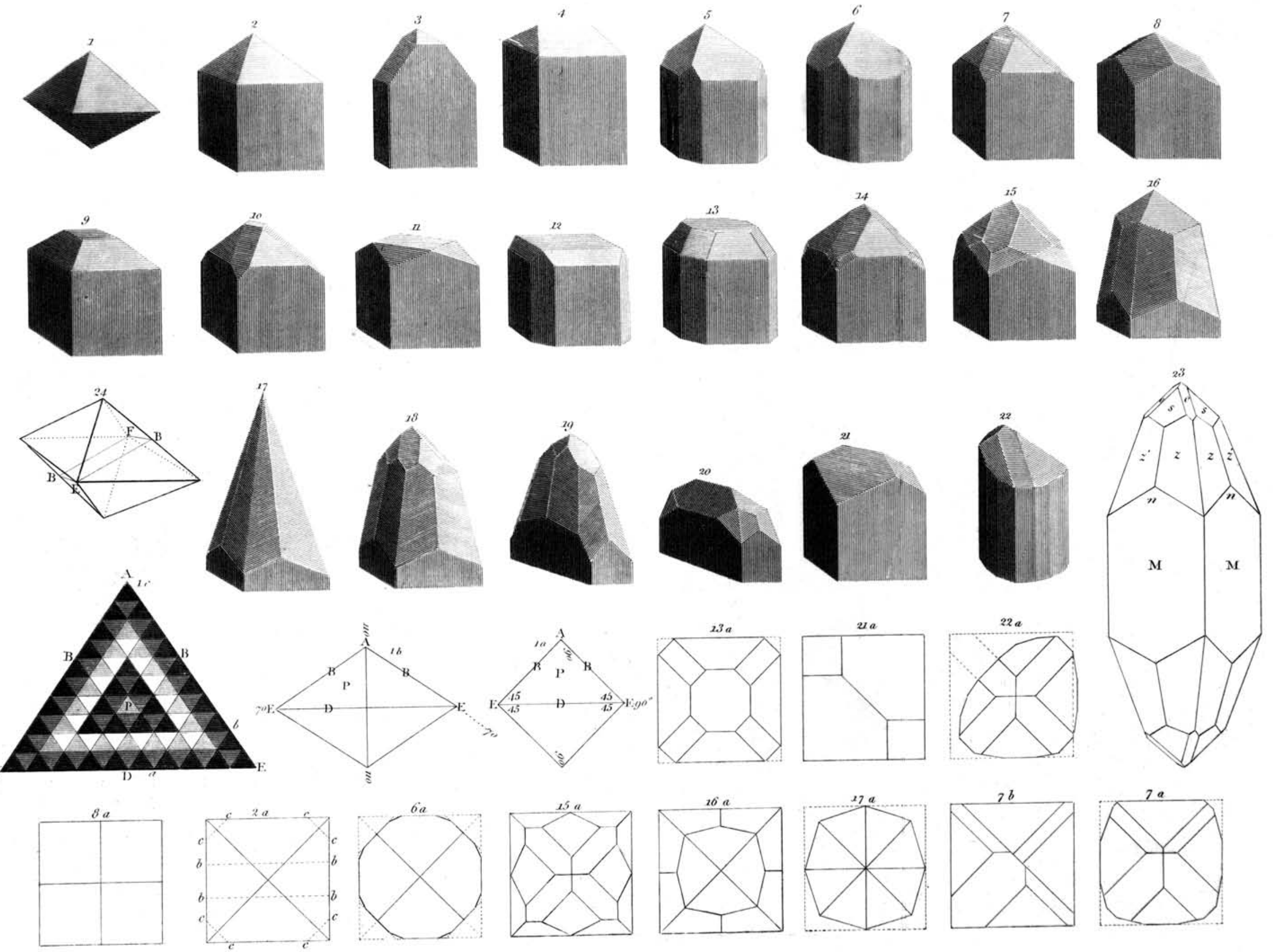
combination of this law with another not yet determined, making the prifm fixteen-fided: fig. $6 a$ is the plan.

$$
\text { Tbird Law of Decrement } \mathrm{B} \times \underset{\mathrm{I}}{\mathrm{D}} \mathrm{s} \text {. }
$$

Fig. 7 thews it incomplete. The plan is thewn, fig. $22 a$, including the dotted lines. Fig. 8, the completion of this law: $8 a$ is the plan. Fig. 22 is an irregular formation, by this law taking place unequally: $22 a$, (without the portion expreffed by the dotted lines, is the plan. The plans of two other unequal accumulations, which difguife the pyramid, are thewn fig. $7 a, 7 b$. Fig. 21 , the fame as fig. 8 , become cuneiform: $21 a$, the plan.

\section{Fourtb Laqu of Decrement A.}

Fig. 9 thews the combination with the firft law: fig. 10, the fame with the third law, incomplete: fig. Ix, the laft completed: fig. 12, the combination with the firt and fecond laws : this, and the combination with the firf law only, are in general peculiar to Bohemian and Saxon ores; the Englin ores exhibit but few examples of them. I have an Englifh cryftal fimilar to fig. 9 , and it is the only one I have feen. Fig. I3, the combination with the fecond and third law: fig. $13 a$ is the plan.

$$
\text { Fiftb Law of Decrement }{ }^{2} \mathrm{E}^{2} \mathrm{D} \text {. }
$$

Fig. 14, the firt indication of this law, in combination with the third law, incomplete. Fig. 15, this law farther extended in the fame combination: ${ }^{5} a$, the plan. Fig. I6, a further extenfion, but fill incomplete: fig. I6 $a$, the plan. Fig. 17 , the completion of this decrement: fig. $17 a$, the plan. Fig. 18, the combination of this law, when arrived at the ftage thewn in fig. 16 , with the third law. Compare fig. 15 and 18 . Fig. 19 and 20 are the fame as fig. 16 , with fome irregularity in the formation.

Thefe five laws of decrement embrace all the varieties of facets $I$ have yet obferved (except thofe mentioned when fpeaking of fig. 6); and by combination, in different ftages 
of each refpectively, produce a great variety of forms, while other varieties arife from difference in colour and tranfparency to which all thefe cryftallifations are fubject.

The macles of De l'Ifle, which Hauy has called bemitrope, or half-turned, may be added as a fupplementary clafs. Of the term macle, De l'Ifle gives this explanation: "When in any cryftal whatever one or more re-entering or internal angles are obferved, we may conclude that it is not a fimple cryftal, but a group of two or more; or even two turned or reverfed moieties of the fame cryftal." De l'Ine was indebted to a Mr. Lermina for determining the direction of the fection which produced the hemitrope cryftals of tin, which he has thewn to be parallel to two oppofite edges of the octaedron. Imagine the primitive octaedron to be divided into halves by a plane paffing diagonally through it, from the centre B, fig. 24 , of one of the edges of the fuperior pyramid; to the centre $B$ of that edge of the inferior pyramid which is diagonally oppofite; the plane will pafs through two oppofite angles $F E$ of the bafe, dividing on each pyramid two adjoining faces into four fcalene triangles, and leaving two adjoining faces perfect, but reverfed on one pyramid in refpect to the other. The plane $\mathrm{FBEB}^{\mathrm{r}}$ of this fection is a rhomb of $60^{\circ}$ and $120^{\circ}$.

The prifmatic cryftals appear to be as furceptible of that fpecies of accumulation which produces the hemitrope as the octaedron, and the fection is always parallel to the one determined above. If the prifm is fhort, and terminated by two pyramids, the fection will pafs through the prifm. into both pyramids, and be irregularly octagon; but if the prifm is long enough to permit the fection to pafs through it without encroaching on the pyramids, it will be a rhomb of $70^{\circ}$ and $110^{\circ}$; the fame as the fection of the primitive octaedron, perpendicular from the apex, and diagonally acrofs the bafe.

I have fome cryftals which are produced by a double fection, and both ends turned on the middle part; others which appear to be only portions taken off the angles at the junc- 
tions of the pyramids to the prifm, and reverfed together without the intermediate part. In fact, the varieties appear to be almoft innumerable.

After I had made the above arrangement, I received the $3^{2 \mathrm{~d}}$ Number of the Journal des Mines, from which I beg leave to fubjoin the following extracts :

"The primitive form of the cryftals of oxydated tin appeared to me to be that of a cube performing the function of a parallelopipedon; fo that the decrements which produce the fecondary forms have, in regard to the' two oppofite faces of the cube, which muft be confidered as the bafes, an action different from that which takes place in regard to the other four faces that reprefent the planes of the prifm." (p. 576.)

"One of the rareft varieties of this kind is that reprefented fig. $7 *$, and which is the feventh of Romé de Lille, T. III. p. 422. We give it the name of difique oxyd of tin; that is to fay, with two ranges of facets. It has altogether thirty-fix faces; four of which $\mathrm{MM}$ are vertical, and on each fide eight inferior oblique $z, z^{\prime}$, and eight fuperior oblique $0, s$. If, as ufual, we denote the edges of the bafe of the cubic nucleus by $B$, and the angles by $A$, we fhall have, as the indicating fign of this variety, $M\left(\stackrel{\frac{1}{3}}{\mathrm{~A}^{2}} \mathrm{~B}^{5}\right) \stackrel{\mathrm{B}^{2}}{\mathrm{~A}}$, in which the intermediary decrement is referred to the facets $z, z^{\prime}$, the decrement $B$ to the facets $s . s$, and the decrement $A$ to the facets 0,0 . The following is the indication of the principal angles: incidence of $\mathrm{M}$ to $\mathrm{M} 90^{\circ}$, of $z$ to $\approx 116^{\circ} 20^{\prime}$, of $z$ to $z^{\prime} 15^{\circ} 30^{\circ}$, of $s$ to $s 120^{\circ}$, of o to $s 150^{\circ}$. Quantity of the angle $n \operatorname{I} 8^{\circ} 4^{\prime} . " \quad$ (Suite de l'Extrait du Traité de Mineralogie de C. Hauy, p. 578.)

From the preceding extracts it appears that Hauy has fuppofed the cube to be the nucleus or primitive form of the oxidated tin cryftals. I have again carefully examined the cryftals in my own collection, and, according to the indi-

* Fig. 23 is a tracing from Hauy's fig. 7 , referred to here, and is the fame cryftal as reprefented fig. I 8 . 
cations obferved on them, from which I have formed my arrangement agreeably to the law laid down by Hauy himfelf, (fee Phil. Mag. Vol. I. p. 292.) I fee no reafon at prefent why I thould alter it. The cryftals of oxidated tin are in general fo hard and brittle that I have not been able to feparate the laminx; and there is nothing to guide the obferver but the direction of the ftria on the fecondary facets. Now the faces, which are parallel to the faces of the octaedron before mentioned, are always very brilliant; but thofe which are on a plane with the edges are friated parallel to thofe edges, particularly thofe cryftals which thew the intermediate ftages of the third law. If the nucleus were a cube, and the laminæ accumulated on it, to form the fecondary cryftals, thewed their direction by ftrix on the new facets, thofe ftrix would be in a direction quite contrary to what are fhewn on thefe cryftals : inftead of going the length of the new facets parallel to the edges of the octaedron, they would crofs the facets perpendicularly to their prefent direction, and it would be impoffible for the cryftal fig. 7 to take the form of fig. 8. In my collection there is a group of opaque black cryftals, fhewing all the variations from the. primitive prifmatic cryfal fig. 2 , to the completion of the third law of decrement fig. 8. In all of them the direction of the frix is very evident. The Saxon and Bohemian ores of in are molt common in the cabinets of France: the cryftals are larger, but do not prefent the varieties of forms that Englith ores do; being mottly confined to the octaedron and its hemitrope, and thofe variations of the fourth law which approach the cube. Had Hauy feen a greater number of the varieties of the Englith tin ores, I think he would, for the primitive form, have had recourfe to the octaedron, which, by a very fimple law of decrement, produces the cube and its varieties that occur in the tin cryftallifations.

To thefe obfervations may be added De l'Ifle's defcription of the fame cryftal that Hauy has defcribed (above), which 
I find to agree fo well with what I have obferved in nature; that I am inclined to fuppofe Hauy's meafures of the angles are given from calculation, affuming the cube as the nucleus, and not from meafurement on the cryftal. De l'Ifle's defcription is as follows :

"I $\mathrm{t}$ is a blackith kind of tin ore, in fmall folitary cryftals five or fix lines in length, and at moft three in breadth. In the variety in queftion, one of the extremities of the rectangular tetraedral prifm firft prefents an octaedral pyramid, the planes of which forming with the prifm an angle of $155^{\circ}$ are irregular pentagons, having one of their angles of $60^{\circ}$, two of $120^{\circ}$, one of $110^{\circ}$, and the molt obtufe of $130^{\circ}$. Thefe pentagons form with each other angles of $1 \times 0^{\circ}$ and $760^{\circ}$. The pyramidal form thence refulting is itfelf terminated by a tetraedral fummit with trapezoidal planes joining at right angles, as is obferved in the ifofceles triangles of the third variety: but this fummit becomes octaedral by the night truncature of its edges, from which refult four linear hexagons that form by their contact at the fummit of the pyramid obtufe angles of $110^{\circ}$. The planes of the prifm, had it not been broken, would be regular hexagons, and the whole cryftal would then have thirty-fix facets." De l'Ifles Cryftallograpbie, Tom. III. p. 423 .

Having faid fo much refpecting the external form, a few remarks concerning the chemical analyfis of tin ores cannot be mifplaced in a paper like the prefent. On this part of the fubject, I cannot do better than by quoting from a paper of C. Guyton, formerly and better known here by the name of De Morveau, whofe chemical authority always carries great weight with it. In his paper entitled, Obfervations on the Acid of Tin, and an Analy/s of its Ores, after giving the analyfes of the brown tin ore of Schlackenwald, as publithed by Mr. Klaproth, which he verified himfelf, and found to contain, tin 75 , iron 0.5 , flex 0.75 , and oxygen $23 \cdot 75=100$; he proceeds to give a reafon why the tin cryl- 
tals are fo infoluble in acids, and combats the idea of Klaproth, that it arifes from fuperfaturation by oxygen, which is diffipated by fluxing the ore with vegetable alkali.

"I believed I had good reafon," fays he, "to doubt that the complete oxygenation, or (if the term be preferred) the fuperfaturation by oxygen, was the true caufe of its infolubility in the muriatic acid; becaufe I could not, at any one inftant of the operation, perceive either the fubftance that fhould take it away, or any of the phenomena that would have accompanied its difengagement. That I might with the greater facility obferve all the circumftances, I operated with a fmall platina crucible over an Argand's lamp. Fifty-five centigrammes of brown cryftals of tin were reduced to a fine powder, and mixed with fix times as much pot-afh (purified by alcohol, and dried): the mixture was moiftened with a few drops of water. I evaporated it firft to drynefs, and then to a commencement of fufion. After the firft treatment, hot water poured on the mafs diffolved more than half the mineral, which was then firf precipitated from it by muriatic acid, and afterwards rediffolved by it with the greateft facility; and the precipitate of the metallic oxyde, reproduced by adding carbonat of pot-afh, was found, as ftated by Klaproth, completely foluble again by the fame acid. After having myfelf witneffed this fact, my firft doubt on the direct caufe of the infolubility of this ore was rather ftrengthened than removed. It cannot be faid that the excefs of oxygen efcaped during the fufion with the pot-ath; for the metal could not form a foluble combination with alkali, unlers it was oxidated in the higheft degree; or, more properly, in the ftate of an acid, fo as that the folution filtered from the refidue thould be a true ftannate, or (if the term be preferred) ftannite of tin $*$

"Now, if we are obliged to admit that all the oxygen of the ore is again found in the alkaline folution, it cannot be the lof of a part of that principle that renders the metal

* The author mult have written Stannite of potafh. $\mathfrak{D}$. 
more foluble in the acid, for it is Atill found in the fame fate of faturation: befides, it does not exhibit any figns of the oxygenated muriatic acid gas; and in this cafe it is difficult to. conceive why there fhould not rather be a difengagement of this gas at the time of digeftion of the acid on the ore, as happens with the oxydes of manganefe and lead.

"To eftablifh this point of theory on a decifive experiment, I diffolved fix grammes of tin in nitrous acid, which I evaporated feveral times to drynefs, adding each time fref acid. I think it cannot be doubted that in this ftate the tin had taken all the oxygen it was capable of fixing; yet the mafs of white oxyd, wafhed till the water that came from it did not in the leaft alter vegetable colours, was readily diffolved in muriatic acid. What then is the caufe of the infolubility of the ore, which alfo is nothing but tin and oxygen, containing hardly 0.01 of extrancous matter? The caufe can only be found in the ftate of aggregation of the latter. This affertion ought not to excite furprife, for hitherto fufficient account has not been taken of this power. If combinations are the refult of affinity or elective attraction, this attraction itfelf is nothing but a power which may be rendered ineffeetual by the fum of the forces which counteract. it. Thefe truths furely will not be denied by:Mr. Klaproth, who has rcndered them fo palpable, by hewing us that the ruby, the fapphire, the adamantine fpar, the elements of which were naturally eafily foluble, refifted the ordinary means of analyfis only by the ftate of the aggregation of their integral parts."

De l'Mle, whofe fccond edition was publhed in 1,83 , conjectured what Guyton here advances from experiment. His words are as follow :- " I cannot agree with Mr. Bergman, that there is no mineralizing fubftance in the cryitals of tin, becaufe, in default of fulphur or arfenic, we ought at leaft to find the acid principle, by the aid of which the metallic earth of tin takes a conftant and determinate cryftalline form." 